\title{
Individual and community-level risk factors of women's acceptance of intimate partner violence in Ethiopia: multilevel analysis of 2011 Ethiopian Demographic Health Survey
}

\author{
Emiru Merdassa Atomssa ${ }^{*^{*}} \mathbb{0}$, Araya Abrha Medhanyie ${ }^{2}$ and Girmatsion Fisseha ${ }^{2}$
}

\begin{abstract}
Background: The prevalence of Intimate partner violence (IPV) is higher in societies with higher acceptance of norms that support IPV. In Ethiopia, the proportion of women's acceptance of IPV was 69\%, posing a central challenge in preventing IPV. The main objective of this study was to assess the individual and community-level factors associated with women's acceptance of IPV.

Methods: Two-level mixed-effects logistic regression was applied to the 2011 Ethiopia Demographic and Health Survey data. A total of 16,366 women nested in the 596 clusters were included in the analysis.

Results: The acceptability of the IPV was estimated to be $69 \%$. Among the individual-level factors: women's education with secondary and above ( $\mathrm{AOR}=0.38 ; 95 \% \mathrm{Cl} 0.29-0.52)$, partner's education secondary and above (AOR $=0.71$; $95 \% \mathrm{Cl} 0.54-0.82$ ), women aged $35-49$ years ( $\mathrm{AOR}=0.67 ; 95 \% \mathrm{Cl} 0.54-0.82$ ), fully empowered in household level

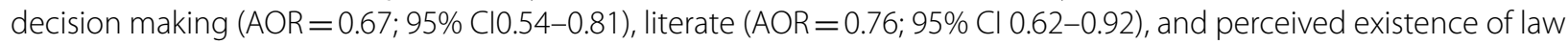
that prevents IPV ( $A O R=0.56 ; 95 \% \mathrm{Cl} 0.50-0.63$ ) were significantly associated with women's acceptance of IPV. Similarly, rural residence $(A O R=1.93 ; 95 \% \mathrm{Cl} 1.53-2.43)$ and living in the State region ( $\mathrm{AOR}=2.37 ; 95 \% \mathrm{Cl} 1.81-3.10$ ) were significantly associated with the women's acceptance of IPV among the community-level factors.

Conclusion: Both individual and community-level factors were significant risk factors for the acceptability of intimate partner violence. Women's education, women's age, women's empowerment, partner education level, perceived existence of the law, and literacy were among individual factors. State region and residence were among community-level risk factors significantly associated women's acceptance of IPV.
\end{abstract}

Keywords: Acceptability of IPV, Individual-level effects, Community-level effects

\section{Background}

Intimate partner violence (IPV) is any behavior within an intimate relationship that causes physical, psychological, or sexual harm to a current or former partner or

\footnotetext{
*Correspondence: emiruydm2016@yahoo.com

1 Department of Public Health, Institute of Health Sciences, Wollega University, Nekemte, Oromia, Ethiopia

Full list of author information is available at the end of the article
}

spouse since the age of $15[1,2]$. Overall, $30 \%$ of women worldwide and $45.6 \%$ of women in Africa experience lifetime prevalence of IPV [1]. In 2005, the World Health Organization conducted the study in ten selected countries: Bangladesh, Brazil, Ethiopia, Japan, Namibia, Peru, Samoa, Serbia and Montenegro, Thailand, and the United Republic of Tanzania [3]. This study reported the highest prevalence of IPV in Ethiopia with a lifetime prevalence (71\%) and 12-months prevalence (54\%). Similarly, the 
previous studies conducted in different parts of Ethiopia showed that the lifetime and past 12 months prevalence of IPV were also high [4-6].

IPV impacts are wide-ranging, resulting in immediate and long-term adverse health outcomes [7, 8]. It affects educational and economic under-performance, unsafe sexual practices, reduced ability to bond as part of parenthood, and increased uptake of health-risk behaviors such as alcohol and illicit drug use [9]. Not only does IPV devastate the lives of women, but it also incurs great costs to the society as a whole. The global economic costs of IPV, including healthcare costs, were estimated to be 4423 billion USD per year, which is approximately $5.18 \%$ of Gross Domestic Product (GDP) [10]. The GDP lost due to IPV-related absenteeism was estimated at $1.5 \%$ of the overall economy, including male and female lost days [11].

Several studies have shown that IPV is always rooted in social, cultural, and attitudes about what is acceptable or what is not acceptable in an intimate relationship [12-14] and some factors increase and create an acceptable climate for violence [3]. The fundamental change to the social attitudes are vital to respond effectively to this problem and reducing the acceptability of all forms of IPV against women has become one of the fundamental goals of public health [15].

In 1993, the United Nations general assembly adopted a landmark declaration on the elimination of violence against women [16]. The acceptability of IPV has been identified as the main reason for delaying the elimination of violence against women (VAW) $[17,18]$. IPV against women is not only a major social and public health problem but also largely undereported: causing an inability to estimate the real magnitude of the problem $[19,20]$.

The prevalence of IPV is higher in societies that have higher women's acceptance of IPV [21]. In Ethiopia, the prevalence of IPV acceptance was $68 \%$ posing a central challenge in preventing IPV [22]. This acceptance contributed to the social climate in which IPV against women is tolerated and legitimized. This lifelong pattern of justifying abusive behaviors and immature self-concepts predisposes women to victims by their partners who seek to fill their power and control needs through disempowerment [22]. This makes IPV eradication difficult.

Acceptance of IPV is a complex problem that needs to be understood within the broader social context, including the family and community [23, 24]. Previous studies have also recommended that research in this area is limited and needs to be conducted by considering the hierarchical nature of the problem [15, 25]. Hence, further research is required to explore factors associated with Women's acceptance of IPV using a multilevel approach. Apart from these, existing literature was limited, inconsistent findings, and not representative of the whole population [25-34]. Thus, this study aimed to answer the following questions: Are individual and community-level factors associated with women's acceptance of IPV? Do communities differ in women's acceptance of Intimate partner violence? Do factors explain the community-level variance in women's acceptance of IPV?

\section{Methods}

\section{Study setting and data source}

Ethiopia is the study area. Administratively, Ethiopia is divided into nine regional states: Tigray, Afar, Amhara, Oromia, Somali, Benishangul, SNNPR, Gambella, Harari and two city administrations: Addis Ababa and Diredawa. The data source is the nationally representative 2011 Ethiopia Demographic Health Survey (EDHS). The survey was a population-based cross-sectional study designed to provide population and health indicator estimates at national and regional levels, as well as urban and rural residents.

\section{Sample size and sampling procedures}

Data from the EDHS 2011 were used, specifically data on individual women of childbearing age. All eligible women in the 624 clusters were the study population. The sample was selected using a stratified, two-stage cluster design and enumeration areas (EAs) were the sampling units for the initial stage of sampling. The sampling frame was a list of all EAs established from the population and housing census in 2007. The first stage involved the selection of clusters. The second stage involved the selection of households from the selected clusters. Following the above procedures at the first stage, the sample contained 624 EAs, but 28 of the clusters were not interviewed because of the drought and security problems in the Somali region. In the second stage, a representative sample of 17,817 households was selected for the survey with 17,385 eligible women identified for individual interviews, and 16,515 women were interviewed. To gain interpretability of results, those who answered don't know and had a missing response for all justifications were excluded. These exclusions resulting in a loss of only $149(0.9 \%)$ women and giving a final sample of 16,366 for the analysis. 


\section{Study variables and measurements}

In lower-income countries, including Ethiopia women's acceptance of IPV were measured using attitudes toward IPV scale of measurement as recommended by the DHS measure [35]. The justification was measured in each survey question by assessing response (yes/no) to five attitudinal scenarios/questions. Women were asked if they felt a husband would be justified in beating his wife if she: goes out without telling him, neglects the children, argues with him, refuses to have sex with him and burns the food. Responses to these questions were transformed into a single dichotomous "Yes" or "No" variable. Women who responded "Yes" to one or several of the questions formed and were coded as Yes (1) and women who responded "no" to all the questions coded as No $(0)$.

The independent variables were socio-economic and demographic characteristics of the respondents (women's education, literacy, partner education, education difference, partner's occupation, women's occupation, owning a house, wealth index, ever chewed chat, alcohol consumption, women's autonomy, marital status, family system, women's age, age at first sex, age at first cohabitation, partner age, number of living children, cohabitation duration, pregnancy status; cultural factors: ethnicity and religion); psychosocial factors (perceived existence of law); and Community-level factors (community literacy, community poverty, community media, community residence and State region).

Women empowerment is measured by women's participation in household decision making concerning who decides on: women's health care, large household purchases, visits to family or relatives and how men's earnings are used were measured in the DHS. If the woman decided jointly with her partner or by herself, she was assigned as participated in decision making and did not otherwise. Further, a new variable 'women empowerment' was created by assuming participation as a proxy measure of women empowerment and leveled into: Empowered if she is involved in four of the decision making, Partially empowered if involved in one of the decisions, two of the decision and three of the decision, and not empowered if not involved in any decision.

Community-level variables were created by aggregating individual's characteristics within their clusters. They were computed using the proportion of selected levels of a given variable that were concerned with per cluster. Since the aggregate values for all generated variables have no meaning at the individual-level, they were categorized into groups based on the national median values. Through this aggregation, the proportion of community factors ranging between 0 and 50th percentiles were categorized as low, and the range between 50 and 100th percentiles were categorized as high. Median values were used because of the non-normality of aggregated variables. Community poverty was constructed from the first two lower quintiles (poorest and poor) as proportions, and distinguishing clusters with low (0-50th percentiles) and high level of community poverty (50-100th percentiles). This procedure was also applied to create community-level factors for community media exposure considering the proportions of community members who have been exposed to any media (listening to the radio, watching television, reading magazines or newspapers) and community literacy (proportion of individuals who were able to read the whole sentence among women in the specified cluster). The two non-aggregate community-level factors included: residence (urban and rural), and contextual region dichotomized into city administration and State region.

\section{Statistical analysis}

The DHS variable recode was designed to standardize variables that would make cross-country analysis easier and comparable. Distribution and values for each variable were assessed to detect implausible values and missing data values managed accordingly. Data were cleaned and analyzed using STATA software version 12.0. Data were examined and summarized using frequency and percent and presented using a table and bar graph. To get a reliable estimate data was given weight to adjust for differences in the probability of selection and non-response. Bivariate multilevel mixed-effects binary logistic regression was used for analyzing the association between explanatory variables and women's acceptance of IPV. Variables with a p-value less than 0.05 in the bivariate analyzes were candidates for the multivariate analysis.

Multivariate two-level mixed-effects logistic regression was applied to the data to predict a binary outcome variable from a set of individual and community-level independent variables. The 2011 EDHS data present a clear multilevel structure and multilevel modeling used to permit the inclusion of error terms that reflect the variation pattern introduced by the data's hierarchical structure. Therefore, this analytic method was employed to account for the hierarchical structure of the data, in which 16,366 individuals (level 1) nested within 596 community groups (level 2).

The proportions of total variance related to community level factors were estimated by the intraclass correlation 
coefficient (ICC). The proportional change in variance $(\mathrm{PCV})$ is the percentage reduction from the estimated variance in the null model as a result of included independent variables in the model. Results of fixed effects were interpreted with an adjusted odds ratio (AOR) with a $95 \%$ confidence interval $(95 \% \mathrm{CI})$. The random effect was interpreted using ICC and PCV and compared across the progressive models by looking at them.

The interaction effect was checked and there was no interaction effect ("Appendix 3"). Moreover, the multicollinearity was also checked by using variance inflation factors (VIF) and no variable had VIF > 10 [36, 37]. Akaike information criterion (AIC) was used to compare models with different sets of parameters. A model with the lowest Akaike Information Criteria (AIC) was considered as the best fit model.

\section{Data quality assurance}

Standard model questionnaires were designed and developed by the DHS program with the basic approach of collecting quality data. Developed English version questionnaires were translated into three major languages Amharigna, Afan Oromo, and Tigrigna. Complete interviews were conducted, yielding a response rate of $95 \%$.

\section{Results}

\section{General background characteristics of study respondents}

In the study sample, $69 \%$ of the women were accepted IPV. Almost half of the women 8303 (50.8\%) had no education and nearly half of the women 5018 (49.7\%) were fully empowered in household decision making. There were 596 clusters which the number of women in each cluster ranged from 5 to 59 . Fifty five percent $(n=317)$ of the clusters had a higher poverty status (Table1). The most frequent reason reported for the women's acceptance of IPV was (52.50\%). when women neglected children The least frequent reason reported was (39.70\%) when women refused to have sex with their husbands (Fig. 1).

\section{Bivariate analysis}

The highest percentage of the acceptance of IPV was reported in women who had no education $(78.91 \%)$ compared to the women who had a secondary or higher education level (34.20\%). Similarly, the acceptance of IPV varies according to the husband's education level. The highest percentage of women's acceptance of IPV was observed among those whose husbands' had no education (85.51\%). Women's acceptance of IPV varies according to their wealth index. The proportion of acceptance of IPV was (80.21\%) among women who were poor compared to women who were rich $(57.24 \%)$. The proportion of women's acceptance of IPV was higher (71.90\%)
Table 1 Characteristics and percentage distribution of women of childbearing age 15-49, accepting attitude of IPV by selected characteristics using 2011 EDHS, Ethiopia

\begin{tabular}{|c|c|c|}
\hline \multirow[t]{2}{*}{ Variables } & \multicolumn{2}{|l|}{ Frequency (\%) } \\
\hline & Unweighted & Weighted \\
\hline \multicolumn{3}{|l|}{ Women's education } \\
\hline No education & $8201(50.11)$ & $8303(50.83)$ \\
\hline Primary & $5807(35.48)$ & $6211(38.02)$ \\
\hline Secondary and above & $2358(14.41)$ & $1820(11.15)$ \\
\hline \multicolumn{3}{|l|}{ Women's age } \\
\hline $15-24$ & $6778(41.42)$ & $6846(41.91)$ \\
\hline $25-34$ & $5246(32.05)$ & $5156(31.57)$ \\
\hline $35-49$ & $4342(26.53)$ & $4332(26.52)$ \\
\hline \multicolumn{3}{|l|}{ Religion } \\
\hline Orthodox & $6929(42.71)$ & $7745(47.82)$ \\
\hline Muslim & $6107(37.64)$ & $4542(28.04)$ \\
\hline Others & $3189(19.65)$ & $3910(24.14)$ \\
\hline \multicolumn{3}{|l|}{ Currently pregnant } \\
\hline No & $15,095(92.23)$ & $15,138(92.67)$ \\
\hline Yes & $1271(7.77)$ & $1196(7.33)$ \\
\hline \multicolumn{3}{|l|}{ Age at first sex } \\
\hline No sex before & $3896(23.83)$ & $4085(25.04)$ \\
\hline$<15$ & $3175(19.42)$ & $3515(21.54)$ \\
\hline $15-17$ & $4936(30.19)$ & $4702(28.82)$ \\
\hline 18 and above & $4343(26.56)$ & $4012(24.60)$ \\
\hline \multicolumn{3}{|l|}{ Women empowerment } \\
\hline Underpowered & $1028(10.33)$ & $883(8.76)$ \\
\hline Partially empowered & $4131(41.52)$ & $4187(41.50)$ \\
\hline Fully empowered & $4791(48.15)$ & $5018(49.74)$ \\
\hline \multicolumn{3}{|l|}{ Women has occupation } \\
\hline No & $7912(48.80)$ & $6919(42.67)$ \\
\hline Yes & $8301(51.20)$ & $9296(57.33)$ \\
\hline \multicolumn{3}{|l|}{ Number of living children } \\
\hline No child & $5686(34.74)$ & $5607(34.32)$ \\
\hline $1-3$ & $5931(36.24)$ & $5702(34.92)$ \\
\hline $4-6$ & $3572(21.83)$ & $3646(22.32)$ \\
\hline 7 and above & $1177(7.19)$ & $1379(8.44)$ \\
\hline \multicolumn{3}{|l|}{ Partner education level } \\
\hline No education & $5856(49.45)$ & $5901(49.94)$ \\
\hline Primary & $4072(34.39)$ & $4560(38.59)$ \\
\hline Secondary and above & $1914(16.16)$ & $1355(11.47)$ \\
\hline \multicolumn{3}{|l|}{ Partner age } \\
\hline $15-24$ & $612(6.06)$ & $648(6.37)$ \\
\hline $25-34$ & 3339 (33.09) & $3339(32.82)$ \\
\hline $35-49$ & $4259(42.21)$ & $4268(41.95)$ \\
\hline 50 and above & $1881(18.64)$ & $1919(18.86)$ \\
\hline \multicolumn{3}{|l|}{ Education difference } \\
\hline The same & $5621(47.49)$ & $5661(47.91)$ \\
\hline Less than him & $4674(39.49)$ & $4629(39.19)$ \\
\hline Greater than him & $1541(13.02)$ & $1524(12.90)$ \\
\hline House owning & & \\
\hline
\end{tabular}


Table 1 (continued)

\begin{tabular}{|c|c|c|}
\hline \multirow[t]{2}{*}{ Variables } & \multicolumn{2}{|l|}{ Frequency (\%) } \\
\hline & Unweighted & Weighted \\
\hline No & $7398(45.23)$ & $6931(42.47)$ \\
\hline Yes & $8957(54.77)$ & $9389(57.53)$ \\
\hline \multicolumn{3}{|l|}{ Wealth index } \\
\hline Poor & $6063(37.05)$ & $5970(36.55)$ \\
\hline Middle & $2251(13.75)$ & $3009(18.42)$ \\
\hline Rich & $8052(49.20)$ & $7355(45.03)$ \\
\hline \multicolumn{3}{|l|}{ Family system } \\
\hline Monogamous & $8777(87.07)$ & 9080 (89.48) \\
\hline Polygamous & $1303(12.93)$ & $1068(10.52)$ \\
\hline \multicolumn{3}{|c|}{ Perceived existence of law against IPV } \\
\hline No & $8632(52.77)$ & $8315(50.92)$ \\
\hline Yes & $7727(47.23)$ & $8014(49.08)$ \\
\hline \multicolumn{3}{|l|}{ Literacy } \\
\hline Illiterate & $11,491(70.41)$ & $11,747(72.19)$ \\
\hline Literate & $4829(29.59)$ & $4526(27.81)$ \\
\hline \multicolumn{3}{|c|}{ Community mass media exposure } \\
\hline Low & $312(52.35)$ & $268(46.59)$ \\
\hline High & $284(47.65)$ & $308(53.41)$ \\
\hline \multicolumn{3}{|l|}{ Community residence } \\
\hline Urban & $184(30.87)$ & $135(23.47)$ \\
\hline Rural & $412(69.13)$ & $441(76.53)$ \\
\hline \multicolumn{3}{|l|}{ Community region } \\
\hline City administration & $96(16.11)$ & $31(5.32)$ \\
\hline State region & $500(83.89)$ & $546(94.68)$ \\
\hline \multicolumn{3}{|l|}{ Community poverty } \\
\hline Low & $286(47.99)$ & $259(44.99)$ \\
\hline High & $310(52.01)$ & $317(55.01)$ \\
\hline \multicolumn{3}{|l|}{ Community literacy } \\
\hline Low & $313(52.52)$ & $297(51.60)$ \\
\hline High & $283(47.48)$ & $279(48.40)$ \\
\hline \multicolumn{3}{|l|}{ IPV justified } \\
\hline No & $5662(34.60)$ & $5032(30.81)$ \\
\hline Yes & $10,704(65.40)$ & 11,302 (69.19) \\
\hline
\end{tabular}

in the State region compared to the city administration. The proportion of acceptance of IPV was higher among women who were living in rural areas (76.25\%). Hence, the acceptance of IPV varies by clusters where women were living. Women who live in the low literacy cluster had higher (79.10\%) acceptance of IPV than women who live in high literacy clusters (Table 2).

\section{The multilevel multivariate logistic model}

Four models were built, the first was the null, the second was individual-level variables, the third was communitylevel variables, and the fourth was the combined (models II and III) which were significant at $p<0.05$. Table 3 presents the multilevel multivariate logistic regression analysis results in which individual characteristics and community-level factors were assessed. The first step in the multilevel modeling was to consider if the data justified the decision to assess random effects at the cluster level. We first fit a simple model (null model) with no covariates in the model, that is, an intercept-only model that predicts the probability of acceptance of IPV. There was a significant variation in the odds of accepting IPV across the clusters $\left(\mathrm{ICC}=0.32, \sigma^{2} \mathrm{u} 0=1.57, p<0.001\right)$. This shows both individual and community-level variables are important in explaining women's acceptance of IPV. The random intercept model variance decreased compared to the random effect of the intercept empty model, from $32 \%$ in the empty model to $12 \%$ in the combined model (model 4), which was attributed to the inclusion of women's and community-level variables (Table 3 ). The combined model showed that $70 \%$ of the variance in women's acceptance of IPV was explained by individual and community-level factors. The reduction of community-level variance was depicted in "caterpillar" plots for shrunken residuals (logarithmic odds ratios) after adjusting for both individual and community-level predictors (Fig. 2). Multicollinearity was checked using the variance inflation factor (VIF); all of the covariates had VIF value



Fig. 1 Reason for accepting IPV among women 15-49 years Ethiopia DHS, 2011 
Table 2 Characteristics and percentage distribution of women of childbearing age 15-49, accepting attitude of IPV by selected characteristics using 2011 EDHS, Ethiopia

\begin{tabular}{ll}
\hline Variables & IPV \\
& $\frac{\text { accepted }}{\text { No Yes }}$ \\
& No Yrude OR $(95 \% \mathrm{Cl})$ \\
\end{tabular}

Women education

No education

Primary

Secondary and above

Women age

$15-24$

$25-34$

$35-49$

Religion

Orthodox

Muslim

Others

Currently pregnant

No

Yes

Age at first sex

No sex before

$<15$

15-17

18 and above

Women empowerment

Underpowered

Partially empowered

Fully empowered

Women has occupation

No

Yes

Number of living children

No child

$1-3$

4-6

7 and above

Partner education level

No education

Primary

Secondary and above

Partnerage

15-24

25-34

35-49

50 and above

Education difference $b / n$ wife \&

Husband

The same

Less than him

Greater than him
$20.1979 .81 \quad 1$

$34.74 \quad 65.26 \quad 0.56(0.52-0.62)$

$65.80 \quad 34.20 \quad 0.20(0.17-0.23)$

$34.35 \quad 65.65 \quad 1$

$29.58 \quad 70.42 \quad 1.10(1.01-1.20)$

$26.67 \quad 73.33 \quad 1.20(1.09-1.32)$

$\begin{array}{lll}35.08 & 64.92 & 1\end{array}$

$28.90 \quad 71.10 \quad 1.68(1.48-1.92)$

$24.83 \quad 75.17 \quad 1.27(1.09-1.49)$

$\begin{array}{lll}31.52 & 68.48 & 1\end{array}$

$21.85 \quad 78.15 \quad 1.17(1.01-1.36)$

$40.85 \quad 59.15 \quad 1$

$21.29 \quad 78.71 \quad 1.73(1.53-1.95)$

$25.95 \quad 74.05 \quad 1.52(1.37-1.69)$

$34.41 \quad 65.59 \quad 1.14(1.03-1.27)$

$11.76 \quad 88.24 \quad 1$

$19.90 \quad 80.10 \quad 0.90(0.73-1.10)$

$33.00 \quad 67.00 \quad 0.49(0.40-0.61)$

$\begin{array}{lll}30.56 & 69.44 \quad 1\end{array}$

$31.01 \quad 68.990 .94(0.87-1.02)$

$\begin{array}{lll}39.59 & 60.41 & 1\end{array}$

$30.21 \quad 69.79 \quad 1.24(1.13-1.35)$

$21.81 \quad 78.19 \quad 1.66(1.49-1.85)$

$21.36 \quad 78.64 \quad 1.54(1.30-1.82)$

$\begin{array}{lll}19.49 & 80.51 \quad 1\end{array}$

$26.7173 .29 \quad 0.71(0.64-0.79)$

$56.77 \quad 43.23 \quad 0.31(0.27-0.37)$

$\begin{array}{lll}20.72 & 79.28 & 1\end{array}$

$25.4974 .510 .84(0.66-1.06)$ *

$27.3972 .61 \quad 0.81(0.65-1.02)$

$24.80 \quad 75.20 \quad 0.85(0.66-1.08)$

$\begin{array}{lll}21.52 & 78.48 & 1\end{array}$

$\begin{array}{lll}29.82 & 70.18 & 0.81 \\ (0.73-0.90)\end{array}$

$35.19 \quad 64.81 \quad 0.65(0.57-0.76)$
Table 2 (continued)

\begin{tabular}{|c|c|c|c|}
\hline \multirow[t]{2}{*}{ Variables } & \multicolumn{2}{|c|}{$\begin{array}{l}\text { IPV } \\
\text { accepted }\end{array}$} & \multirow[t]{2}{*}{ Crude OR $(95 \% \mathrm{Cl})$} \\
\hline & No & Yes & \\
\hline \multicolumn{4}{|l|}{ House owning } \\
\hline No & 42.11 & 57.89 & 1 \\
\hline Yes & 22.51 & 77.49 & $1.58(1.45-1.72)$ \\
\hline \multicolumn{4}{|l|}{ Wealth index } \\
\hline Poor & 19.79 & 80.21 & 1 \\
\hline Middle & 23.45 & 76.55 & $0.90(0.78-1.02)$ \\
\hline Rich & 42.76 & 57.24 & $0.51(0.45-0.58)$ \\
\hline \multicolumn{4}{|l|}{ Family system } \\
\hline Monogamous & 26.23 & 73.77 & 1 \\
\hline Polygamous & 21.98 & 78.02 & $1.07(0.91-1.27)^{*}$ \\
\hline \multicolumn{4}{|c|}{ Perceived existence of law against IPV } \\
\hline No & 21.61 & 78.39 & 1 \\
\hline Yes & 40.37 & 59.63 & $0.50(0.46-0.54)$ \\
\hline \multicolumn{4}{|l|}{ Literacy } \\
\hline Illiterate & 22.43 & 77.57 & 1 \\
\hline Literate & 52.08 & 47.92 & $0.36(0.33-0.39)$ \\
\hline \multicolumn{4}{|c|}{ Community mass media exposure } \\
\hline Low & 20.93 & 79.07 & 1 \\
\hline High & 38.87 & 61.13 & $0.26(0.22-0.32)$ \\
\hline \multicolumn{4}{|c|}{ Community residence } \\
\hline Urban & 53.42 & 46.58 & 1 \\
\hline Rural & 23.75 & 76.25 & $5.69(4.76-6.80)$ \\
\hline \multicolumn{4}{|l|}{ Community region } \\
\hline City adminstration & 74.29 & 25.71 & 1 \\
\hline State region & 28.10 & 71.90 & $6.39(5.00-8.16)$ \\
\hline \multicolumn{4}{|l|}{ Community poverty } \\
\hline Low & 41.39 & 58.61 & 1 \\
\hline High & 21.68 & 78.32 & $3.71(3.07-4.48)$ \\
\hline \multicolumn{4}{|l|}{ Community literacy } \\
\hline Low & 20.90 & 79.10 & 1 \\
\hline High & 40.84 & 59.16 & $0.24(0.20-0.29)$ \\
\hline
\end{tabular}

less than 10, confirming that there was no indication for severe multicollinearity ("Appendix 3 "). The AIC values of progressive models were computed and compared. Among the candidate models, the final fitted model with the least value of AIC 9698.32 (Table 3).

\section{Measures of associations (fixed effects)}

In this study, a multilevel multivariate binary logistic regression model was employed. The results of the fixed part of the random coefficient model showed that women's education, women's age, husband's education, women's empowerment, perceived existence of law against IPV, Literacy of women, community poverty, place of residence, and contextual region and residents 
Table 3 Multivariate two-level mixed-effects logistic regression of women aged 15-49 years, acceptability of IPV in 2011 EDHS, Ethiopia

\begin{tabular}{|c|c|c|c|c|}
\hline Variables & Model-I & Model-II AOR (95\% Cl) & Model-III AOR (95\% Cl) & Model-IV AOR (95\% CI) \\
\hline \multicolumn{5}{|l|}{ Women's education } \\
\hline No education & & 1 & & 1 \\
\hline Primary & & $0.77(0.64-0.92)$ & & $0.77(0.66-0.89)$ \\
\hline $2^{\text {nd }}$ and above & & $0.35(0.25-0.48)$ & & $0.38(0.29-0.52)$ \\
\hline \multicolumn{5}{|l|}{ Women's age } \\
\hline $15-24$ & & 1 & & 1 \\
\hline $25-34$ & & $0.69(0.58-0.82)$ & & $0.74(0.62-0.88)$ \\
\hline $35-49$ & & $0.62(0.50-0.77)$ & & $0.67(0.54-0.82)$ \\
\hline \multicolumn{5}{|l|}{ Religion } \\
\hline Orthodox & & 1 & & \\
\hline Muslims & & $1.04(0.89-1.23)$ & & \\
\hline Others & & $1.24(1.02-1.51)$ & & \\
\hline \multicolumn{5}{|l|}{ Currently pregnant } \\
\hline No & & 1 & & \\
\hline Yes & & $1.00(0.85-1.18)$ & & \\
\hline \multicolumn{5}{|l|}{ Age at first sex } \\
\hline No sex before & & 1 & & \\
\hline$\leq 14$ & & $0.39(0.06-2.42)$ & & \\
\hline $15-17$ & & $0.36(0.06-2.22)$ & & \\
\hline $18+$ & & $0.33(0.05-2.02)$ & & \\
\hline \multicolumn{5}{|l|}{ Women empowerment } \\
\hline Underpowered & & 1 & & 1 \\
\hline Partially empowered & & $1.06(0.87-1.30)$ & & $1.07(0.87-1.31)$ \\
\hline Fully empowered & & $0.64(0.52-0.78)$ & & $0.67(0.54-0.81)$ \\
\hline \multicolumn{5}{|l|}{ Number of living children } \\
\hline no child & & 1 & & \\
\hline $1-3$ & & $0.95(0.78-1.15)$ & & \\
\hline $4-6$ & & $1.17(0.93-1.48)$ & & \\
\hline 7 and above & & $1.10(0.83-1.46)$ & & \\
\hline \multicolumn{5}{|l|}{ Partner education level } \\
\hline No education & & 1 & & 1 \\
\hline Primary & & $0.71(0.57-0.87)$ & & $0.86(0.75-0.98)$ \\
\hline 2nd and above & & $0.53(0.39-0.72)$ & & $0.71(0.54-0.82)$ \\
\hline \multicolumn{5}{|l|}{ Education difference } \\
\hline Same as husband & & 1 & & 1 \\
\hline Less than husband & & $1.28(1.04-1.58)$ & & $1.26(1.02-1.56)$ \\
\hline Greater than husband & & $1.21(0.98-1.49)$ & & $1.21(0.98-1.50)$ \\
\hline \multicolumn{5}{|l|}{ House owning } \\
\hline No & & 1 & & 1 \\
\hline Yes & & $1.50(1.30-1.72)$ & & $1.00(0.81-1.25)$ \\
\hline \multicolumn{5}{|l|}{ Wealth index } \\
\hline Poor & & 1 & & 1 \\
\hline Middle & & $1.06(0.89-1.25)$ & & $1.07(0.91-1.27)$ \\
\hline Rich & & $0.72(0.62-0.84)$ & & $0.90(0.76-1.06)$ \\
\hline \multicolumn{5}{|c|}{ Perceived existence of law against IPV } \\
\hline No & & 1 & & 1 \\
\hline Yes & & $0.54(0.48-0.60)$ & & $0.56(0.50-0.62)$ \\
\hline
\end{tabular}


Table 3 (continued)

\begin{tabular}{|c|c|c|c|c|}
\hline Variables & Model-I & Model-II AOR (95\% CI) & Model-III AOR (95\% Cl) & Model-IV AOR $(95 \% \mathrm{CI})$ \\
\hline \multicolumn{5}{|c|}{ Literacy status of women } \\
\hline Illiterate & & 1 & & 1 \\
\hline Literate & & $0.69(0.56-0.84)$ & & $0.76(0.62-0.92)$ \\
\hline \multicolumn{5}{|l|}{ Community region } \\
\hline City adminstration & & & 1 & 1 \\
\hline State region & & & $2.67(2.09-3.40)$ & $2.37(1.81-3.10)$ \\
\hline \multicolumn{5}{|c|}{ Community media exposure } \\
\hline Low & & & 1 & \\
\hline High & & & $0.86(0.70-1.06)$ & \\
\hline \multicolumn{5}{|c|}{ Community residence } \\
\hline Urban & & & 1 & 1 \\
\hline Rural & & & $2.43(1.94-3.06)$ & $1.93(1.53-2.43)$ \\
\hline \multicolumn{5}{|l|}{ Community poverty } \\
\hline Low & & & 1 & 1 \\
\hline High & & & $1.39(1.04-1.86)$ & $1.40(1.05-1.87)$ \\
\hline \multicolumn{5}{|l|}{ Community literacy } \\
\hline Low & & & 1 & 1 \\
\hline High & & & $0.66(0.54-0.80)$ & $0.98(0.79-1.22)$ \\
\hline \multicolumn{5}{|c|}{ Random effect measure } \\
\hline ICC & 0.32 & 0.17 & 0.14 & 0.12 \\
\hline PCV & Reference & 56.40 & 67.04 & 70.00 \\
\hline \multicolumn{5}{|l|}{ Model fitness } \\
\hline AlC & $18,239.75$ & 9825.51 & $17,780.76$ & 9698.32 \\
\hline
\end{tabular}

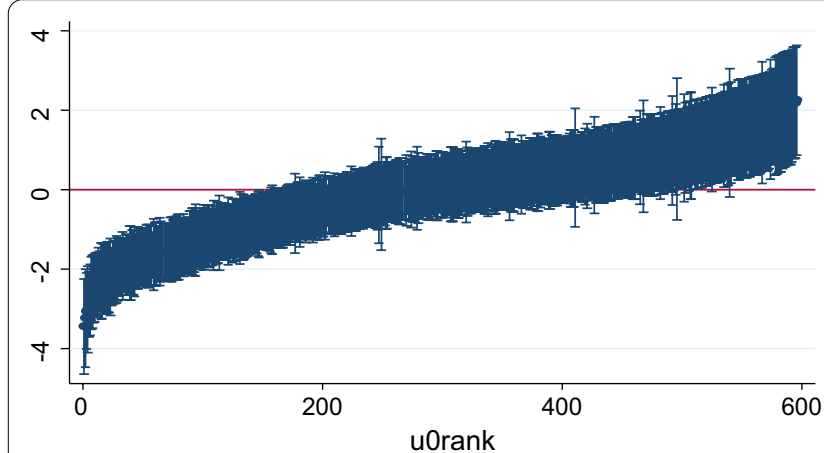

Before

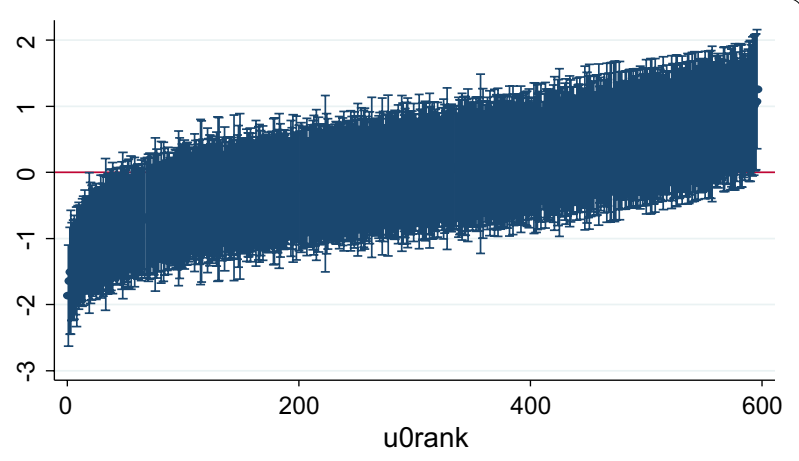

After

Fig. 2 Caterpillar plot before and after predictor variables (individual-level and community-level) entry to the model

were significantly associated with acceptance of IPV among community-level factors (Table 3).

Independent of other factors, compared to women no education, primary (Adjusted odds ratio [AOR] $0.77 ; 95 \% \mathrm{CI}$ 0.66-0.89) and secondary and above $(\mathrm{AOR}=0.38 ; 95 \% \mathrm{CI} 0.29-0.52)$ were less likely to have accepted IPV. Further, the results showed that women's whose husbands had a primary education level $(\mathrm{AOR}=0.86$; 95\% CI $0.75-0.98)$ and secondary and above $(\mathrm{AOR}=0.71 ; 95 \% \mathrm{CI} 0.54-0.82$ ) had lower odds of justifying IPV compared to women whose husbands had no education. Compared with women aged 
15-24 years, women aged 25-34 years $(\mathrm{AOR}=0.74$; 95\% CI $0.62-0.88)$ and $35-49$ years $(\mathrm{AOR}=0.67 ; 95 \%$ CI 0.54-0.82) were less likely to have accepted IPV.

The odds of accepting IPV were less likely for women who were fully empowered than women who were unempowered in domestic decision making $(\mathrm{AOR}=0.67 ; 95 \% \mathrm{CI}$ 0.54-0.81). Women who thought or perceived the existence of a law that prevents IPV were less likely to have accepted IPV than women who didn't (AOR $=0.56,95 \%$ CI 0.50-0.63). Literate women were less likely to have accepted IPV (AOR $=0.76,95 \%$ CI 0.62-0.92) when compared to illiterate women.

Compared with women from the city administration, women from the State region $(\mathrm{AOR}=2.37,95 \% \mathrm{CI}$ 1.81-3.10) were more likely to have accepted IPV. Residence was also significantly associated with acceptance of IPV (AOR $=1.93$, 95\% CI 1.53-2.43). See Table 3.

\section{Discussion}

The study set out to investigate individual-level and community-level risk factors of Women's acceptance of IPV. Both individual-level and community-level factors are important predictors of women's acceptance of IPV. The multilevel logistic regression analysis result showed that women's education, women's age, husband's education, women empowerment, literacy, and perceived existence of law were the main predictors among individual-level predictors, and contextual region and residents were significantly associated with accepting attitude of IPV among community-level factors.

This study showed that women with higher education levels had lower odds of accepting IPV. Some of the previous studies were comparable to this finding $[27,33]$. In contrast to a study conducted in four provinces of Philippines showed that women's education had no significant association with IPV acceptance. In that study, a small sample size was used which might have contributed to the difference [28]. Women's husbands who had a higher education level had lower odds of IPV acceptance than women whose husbands had no education. This showed that education could help women understand what is right about IPV and strengthen their attitudes that support victim safety and personal relevance to make appropriate decisions.

In this study, the likelihood of women's acceptance of IPV was less for older women. This finding is consistent with the results of different studies undertaken in Asian countries and Africa [25, 38]. Early life and socialization might influence them to accept IPV [39] and possibly young women closer to the family for witnessing parental violence, had higher odds of accepting IPV [40].

Women's empowerment was a protective factor against acceptance of IPV. Women who had fully empowered in domestic decision making were less likely to have accepted IPV compared to underpowered women. This finding was similar to those of studies conducted in the Niger Delta and Bangladesh [31, 34]. Empowerment might contribute to the increasing confidence to justify what is acceptable to them and might influence women's views toward equality in a relation, rather than accepting violence. Women's empowerment is vital, as is changing social norms and notions of masculinity associated with power and dominance.

In this study, the literate woman was shown to be less likely to have accepted IPV than illiterate women. The evidence from a comparative study conducted in two countries, Kenya and Zambia supported this finding [41]. This might be because literate women have better access to information and education, which might influence and shape women's attitudes and learn what is acceptable and unacceptable.

This study also investigated contextual factors of women's acceptance of IPV. Women living in rural areas were more likely to have accepted IPV than women residing in urban areas. This is similar to studies conducted in Sub-Saharan Africa [38, 42, 43]. The contextual region was also significantly associated with women's acceptance of IPV. There were regional differences in the odds of acceptance of IPV. This might be because the State regions were more likely to have accepted IPV compared to City administrations. State regions were less urbanized, educated women, and had low media exposure compared to the city administration. In addition, dissimilarity might be due to the contribution of different factors specific to the region (community norms, beliefs, customs, and others) that may explain the differences.

Th study findings were interpreted within the context of some study limitations and strengths. This study might be influenced by self-reported measures of attitudes and unavailability of important variables in 2011 EDHS data, such as the history of childhood abuse, women's family history, beliefs, and other cultural factors [24]. This study utilized cross-sectional data as there is no evidence of a temporal relationship between risk factors and women's 
acceptance of IPV. This study conducted nationally representative data, which enables the generalisability at national level. This study also provides important insights into both individual and contextual factors influencing accepting attitudes of IPV using appropriate statistical modeling.

\section{Conclusions}

This study suggests that both individual and community-level risk factors substantially affect the acceptance of IPV in Ethiopia. Women's education, women's age, women's empowerment, partner education level, perceived existence of the law, and literacy were among the individual factors. State region and residence were among community-level risk factors that significantly associated the acceptance of IPV.

\section{Appendixies}

Appendix 1

See Table 4.

Table 4 Interaction and confounding effect test output

\begin{tabular}{|c|c|c|c|c|c|c|c|c|}
\hline \multirow{2}{*}{$\begin{array}{l}\text { Suspected variables } \\
\text { Product terms }\end{array}$} & \multirow[t]{2}{*}{ Level } & \multirow[t]{2}{*}{$\beta$ Coef without $x$} & \multirow[t]{2}{*}{$\beta$ Coef with $x$} & \multirow[t]{2}{*}{$\Delta \beta$ coef } & \multirow{2}{*}{$\begin{array}{l}\text { Percent } \\
\text { (wot-wz)/ } \\
w^{*} 100 \%\end{array}$} & \multirow[t]{2}{*}{$P$ value } & \multicolumn{2}{|l|}{ Result } \\
\hline & & & & & & & Interaction & Confounding \\
\hline \multirow[t]{2}{*}{ Cohabdur*weduc } & 1 & -0.1798017 & -0.2219209 & -0.0421192 & 18.97937508 & NS & & \\
\hline & 2 & 0.1071532 & 0.0312903 & -0.0758629 & -242.4486183 & & & \\
\hline Litstat*weduc & 1 & -0.6564755 & -0.2822647 & 0.3742108 & -132.5744239 & NS & & \\
\hline \multirow[t]{2}{*}{ Cohabdur*wage } & 1 & -0.3284976 & -0.2219209 & 0.1065767 & -48.024634 & NS & & \\
\hline & 2 & -0.2366632 & 0.0312903 & 0.2679535 & 856.3468551 & & & \\
\hline Litstat*wempoerement & 1 & -0.3699463 & -0.2822647 & 0.0876816 & -31.06360802 & NS & & \\
\hline \multirow[t]{2}{*}{ Empower*perexilaw } & 1 & 0.0055333 & 0.0720158 & 0.0664825 & 92.3165472 & NS & & \\
\hline & 2 & -0.4729046 & -0.4063732 & 0.0665314 & -16.371995 & & & \\
\hline \multirow[t]{2}{*}{ Cohabdur*perexilaw } & 1 & -0.235816 & 0.2354489 & 0.4712649 & 200.1559149 & NS & & \\
\hline & 2 & 0.0046744 & -0.2219209 & -0.2265953 & 102.1063361 & & & \\
\hline \multirow[t]{2}{*}{ Weduc*litstat } & 1 & -0.3513471 & -0.2676568 & 0.0836903 & -31.26776529 & NS & & \\
\hline & 2 & -1.218405 & -0.9687526 & 0.2496524 & -25.77050116 & & & \\
\hline \multirow[t]{2}{*}{ Meduc*resid } & 1 & -0.1899441 & -0.154473 & 0.0354711 & -22.96265367 & NS & & \\
\hline & 2 & -0.4400745 & -0.3446921 & 0.0953824 & -27.67176851 & & & \\
\hline Ownhouse ${ }^{*}$ resid & 1 & 0.30346 & 0.2354489 & -0.0680111 & -28.88571575 & NS & & \\
\hline
\end{tabular}

NS non-significant 


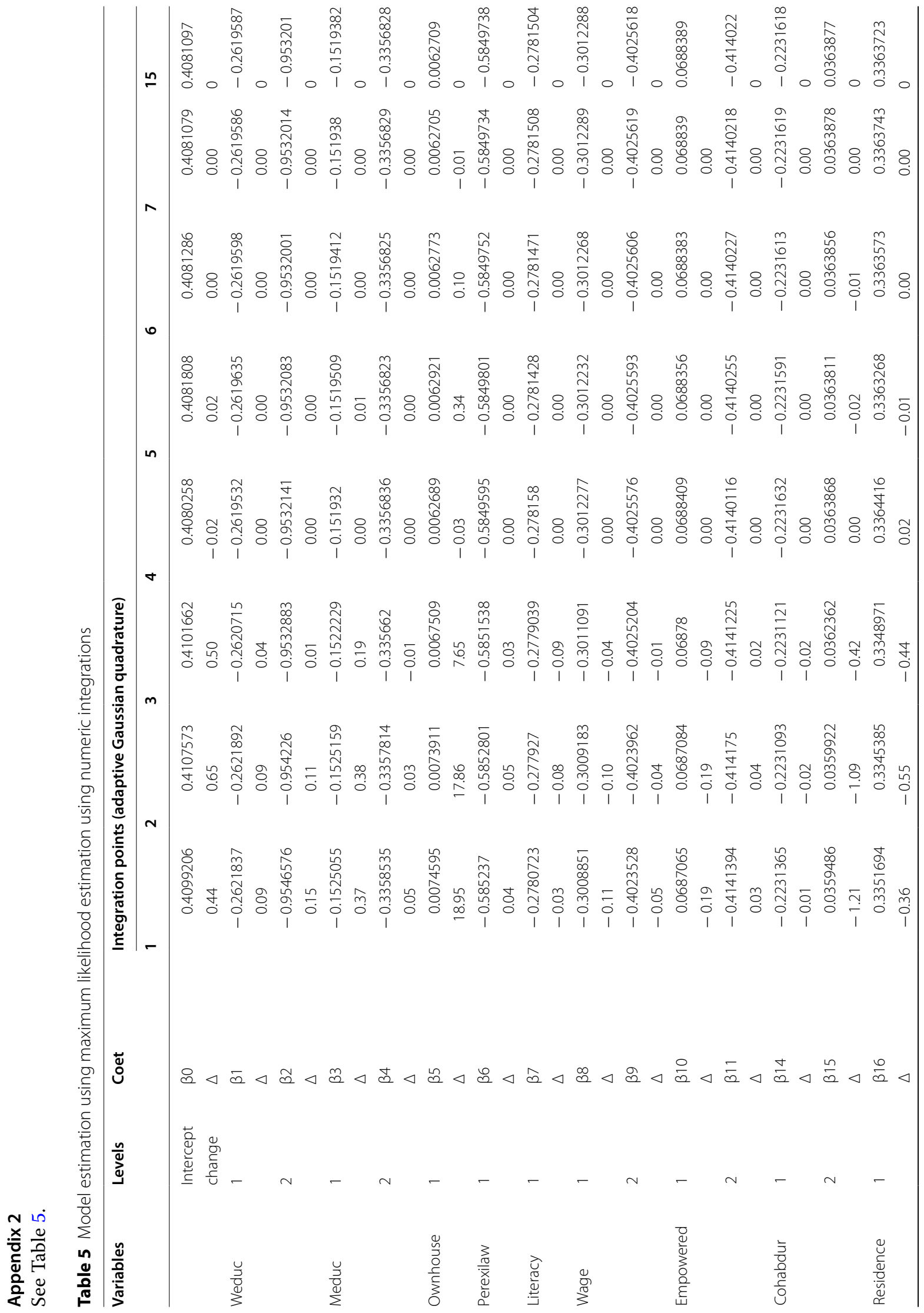




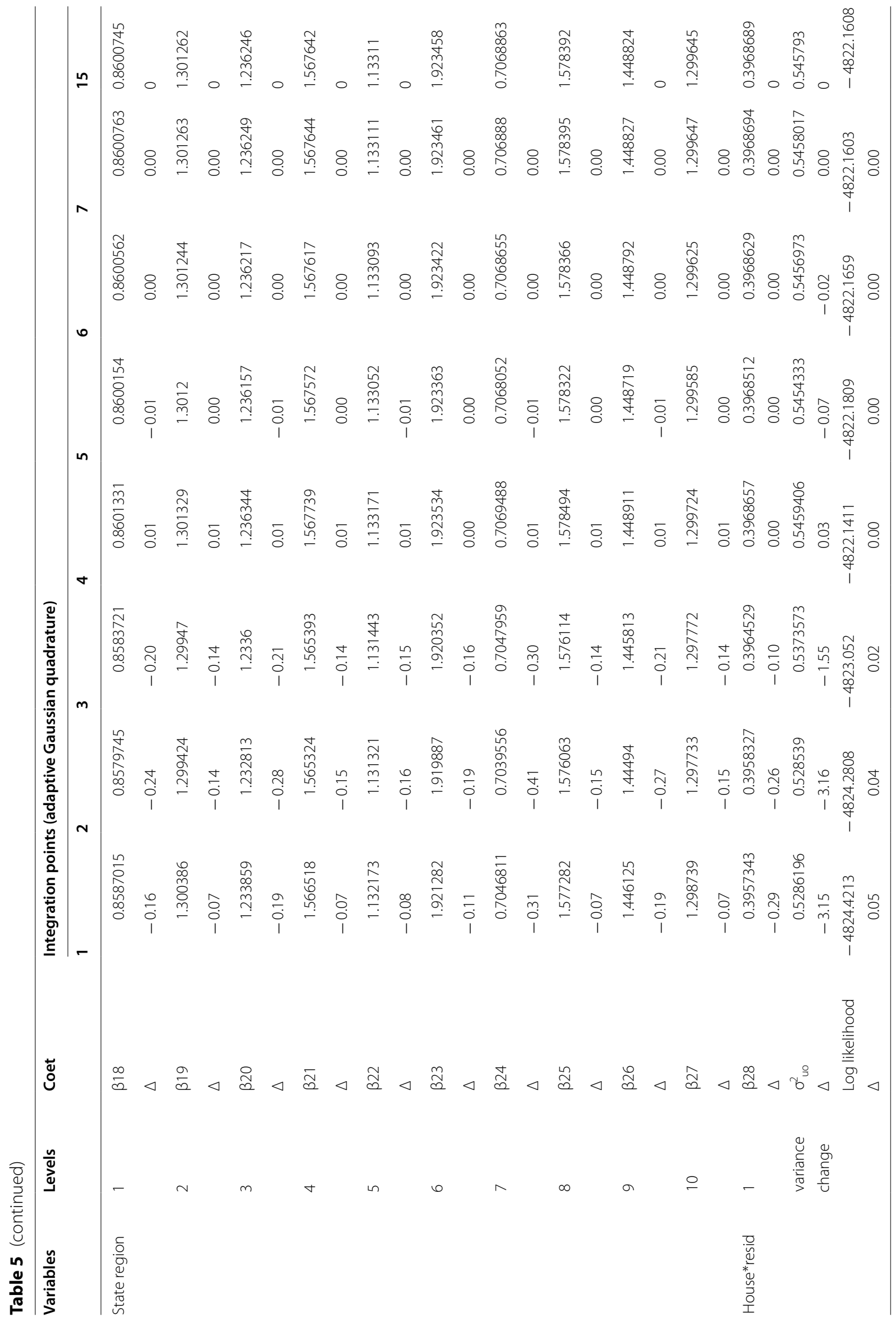




\section{Appendix 3}

See Table 6.

Table 6 Multicollinearity test output of covariates

\begin{tabular}{lll}
\hline variables & VIF & $\frac{1}{V I F}$ \\
\hline Women education & 4.08 & 0.245359 \\
Partner education & 3.00 & 0.333296 \\
Women age & 6.15 & 0.162503 \\
Women empowerment & 6.15 & 0.162503 \\
Cohabitation duration & 8.59 & 0.116407 \\
Perceived existence of law & 1.91 & 0.523432 \\
Literacy status & 2.88 & 0.347195 \\
State region & 4.35 & 0.230138 \\
Own living house & 1.42 & 0.702731 \\
Residence & 1.65 & 0.605906 \\
Mean VIF & 4.01 & 0.249376 \\
\hline
\end{tabular}

\section{Appendix 4}

See Table 7. participated in writing the original draft of the paper and contributed to the final version of the paper and act as guarantors.

\section{Funding}

This study was financially supported by Mekelle University for analyzing the data, interpreting the result and writing the manuscript.

\section{Declarations}

\section{Ethics approval and consent to participate}

Ethical approval for the 2016 EDHS was provided by the Ethiopian Health and Nutrition Research Institute Review Board, the National Research Ethics Review Committee at the Ministry of Science and Technology, the Institutional Review Board of ICF International, and the communicable disease control (CDC). Also, written consent for participation was obtained from each respondent as it was indicated in the EDHS 2011 publications at https://dhsprogram.com/pubs/ pdf/FR255/FR255.pdf. To access the data, online registration was requested by authors at the website "http://dhsprogram.com/data". Hence a research project request form was filled including a project title and a description of the analysis proposed to perform with the data.

\section{Consent to publication}

Not applicable.

\section{Availability of data and materials}

Data are available from the 2011 Ethiopian Demographic Health Survey Institutional Data Access/ Ethics Committee for researchers who meet the criteria for access to confidential data. Now it is available and can be obtained from the corresponding author.

Table 7 Hosmer-Lemshow goodness of fit test

\begin{tabular}{|c|c|c|c|c|c|c|c|}
\hline Group & Prob & Obs_1 & Exp_1 & Obs_0 & Obs_1 & Total & $\begin{array}{l}\text { Hosmer- } \\
\text { Lemeshow } \\
\text { chi2(Sig) }\end{array}$ \\
\hline 1 & 0.3740 & 238 & 229.4 & 745 & 753.6 & 983 & $9.10(0.3337)$ \\
\hline 2 & 0.5808 & 464 & 478.3 & 517 & 502.7 & 981 & \\
\hline 3 & 0.6895 & 647 & 638.4 & 345 & 353.6 & 992 & \\
\hline 4 & 0.7388 & 693 & 699.1 & 284 & 277.9 & 977 & \\
\hline 5 & 0.7810 & 764 & 744.3 & 213 & 232.7 & 977 & \\
\hline 6 & 0.8110 & 814 & 833.9 & 232 & 212.1 & 1046 & \\
\hline 7 & 0.8393 & 774 & 758.1 & 144 & 159.9 & 918 & \\
\hline 8 & 0.8665 & 827 & 837.4 & 155 & 144.6 & 982 & \\
\hline 9 & 0.8909 & 865 & 866.6 & 122 & 120.4 & 987 & \\
\hline 10 & 0.9483 & 890 & 890.3 & 87 & 86.7 & 977 & \\
\hline
\end{tabular}

\section{Abbreviations}

AIC: Akaike Information Criterion; CSA: Central Statistical Agency; DHS: Demographic Health Survey; EAs: Enumeration Areas; EDHS: Ethiopian Demographic Health Survey; GDP: Growth Domestic Product; ICC: Intraclass Correlation Coefficient; IPV: Intimate Partner Violence; PSU: Primary Sampling Unit; PCV: Proportion Change Variance; SSA: Sub-Saharan Africa; USD: United State Dollar; WHO: World Health Organization.

\section{Acknowledgements}

Authors are thankful to the DHS measure for permission to use the data. We are also thankful to Mekelle University for funding this work.

\section{Authors' contributions}

EM, AA and GF were actively involved in the planning and design of the study, analyzing and interpreting the data and discussing the findings. All authors

\section{Competing interests}

The authors declare that they have no competing interests.

\section{Author details}

${ }^{1}$ Department of Public Health, Institute of Health Sciences, Wollega University, Nekemte, Oromia, Ethiopia. ${ }^{2}$ School of Public Health, College of Health Sciences, Mekelle University, Mekelle, Tigray, Ethiopia.

Received: 30 April 2020 Accepted: 21 July 2021 Published online: 04 August 2021

References

1. World Health Organization. London school of Hygiene and Tropical medicine, and South African medical and research council, Global and 
regional estimates of violence against women. Geneva: World Health Organization; 2013.

2. Dartmouth Model United Nations. Commission on the Status of Women (CSW), in Ninth Annual Conference, Della Jung, et al., Editors. 2014, Dartmouth Model United Nations: Hanover.

3. García-Moreno C, et al. WHO multi-country study on women's health and domestic violence against women. World Health Organization. 2005;368:1260-9.

4. Abeya SG, Afework MF, Yalew AW. Intimate partner violence against women in western Ethiopia: prevalence, patterns, and associated factors. BMC Public Health. 2011:11:913.

5. Semahegn A, Belachew T, Abdulahi M. Domestic violence and its predictors among married women in reproductive age in Fagitalekoma Woreda, Awi zone, Amhara regional state, North Western Ethiopia. Reprod Health. 2013:10:63.

6. Campbell JC. Health consequences of intimate partner violence: violence against women II. The Lancet. 2002;359:1232-7.

7. Vives-Cases $C$, et al. The effect of intimate partner violence and other forms of violence against women on health. J Public Health. 2010:33(1):15-21.

8. World Health Organization and Pan Africa Health Organization. Understanding and addressing violence against women. In: Intimate partner violence. 2012.

9. Kaur R, Garg S. Addressing domestic violence against women: an unfinished agenda. Indian J Community Med. 2008;33(2):73-6.

10. Fearon J, Hoeffler A. Benefits and costs of the conflict and violence targets for the post-2015 development agenda. Copenhagen; 2014

11. Duvvury $\mathrm{N}$ et al. Intimate partner violence: economic costs and Implications for Growth and Development. In: Women's voice, agency, \& participation. 2013. World Bank.

12. Jewkes R. Intimate partner violence: causes and prevention. The Lancet. 2002;359:1423-9.

13. Rasoulian M, et al. Risk factors of domestic violence in Iran. J Environ Public Health. 2014;52:9.

14. Linos N, Kawachi I. Community social norms as social determinants of violence against women. Am J Public Health. 2012;102(2):199-200.

15. Black MC et al. The National Intimate Partner and Sexual Violence Survey, in 2010 summary report. 2011, Centers for Disease Control and Prevention: Atlanta.

16. United Nations General Assembly (UNGA). Declaration on the elimination of violence against women. In: Proceedings of the 85th plenary meeting. 1993. Geneva

17. Rosche D. How to eliminate violence against women beyond 2015. In: Dawe A (ed). 2014, OXFAM.

18. Thomson M. Addressing gender based violence in the post 2015 agenda. In: Irish consortium on gender based violence. 2012.

19. Gracia E. Unreported cases of domestic violence against women: towards an epidemiology of social silence, tolerance, and inhibition. J Epidemiol Community Health. 2004;58:536-7.

20. Tashkandi AA, Rasheed P. Wife abuse: a hidden problem. A study among Saudi women attending PHC centres. East Mediterr Health J. 2009;15(5):1242-53.

21. Garcia-Moreno C, Watts C. WHO multi-country study on women's health and domestic violence. Bull World Health Organ. 2011;89(2):184-94.

22. Ethiopian Central Statistical Agency and ICF International. Ethiopia demographic and health survey 2011 report. 2012, Central statistical agency and ICF International: Addis Ababa,Ethiopia and Calverton, Maryland, USA.

23. Heise L. Violence against women: an integrated, ecological framework. Violence Against Women. 1998;4(3):262.
24. Flood $M$, Pease B. Factors influencing attitudes to violence against women. Trauma Violence Abuse. 2009;20(10):125-42.

25. Hindin MJ. Understanding women's attitudes towards wife beating in Zimbabwe. Bull World Health Organ. 2003;81:501-8.

26. Yount K, Li L. Women's Justification of domestic violence in Egypt. J Marriage Fam. 2009;71:1125-40.

27. Gharaibeh MK, Abu-Baker NN, Aji S. Attitudes toward and justification for wife abuse among syrian medical and nursing students. J Transcult Nurs. 2012;23:297.

28. Natividad JN. Is wife beating justifiable? A comparison of men and women's views from four of the ten poorest provinces in the Philippines In: 12th National Convention on Statistics (NCS). EDSA Shangri-La Hotel, Mandaluyong City. 2013.

29. Rani M, Bonu S. Attitudes toward wife beating: a cross-country study in Asia. J Interpers Violence. 2009;24(8):1371-97.

30. Antai $D$, Antai J. Attitudes of women toward intimate partner violence: a study of rural women in Nigeria. Int Electr J Rural Remote Health Res Educ Pract Policy. 2008:8:996.

31. Antai D, Antai J. Collective violence and attitudes of women toward intimate partner violence: evidence from the Niger Delta. BMC Int Health Hum Rights. 2009;9:12.

32. Akmatov MK, et al. Factors associated with wife beating in Egypt: analysis of two surveys (1995 and 2005). BMC Womens Health. 2008;8:15.

33. Dhaher EA, et al. Attitudes toward wife beating among palestinian women of reproductive age from three cities in West Bank. J Interpers Violence. 2010;25:518.

34. Yount KM, et al. Indeterminate responses to attitudinal questions about Intimate Partner Violence against women in rural Bangladesh. Popul Res Policy Rev. 2012:31:797-830.

35. Yount KM, et al. Measuring attitudes about intimate partner violence against women: the ATT-IPV scale. Demography. 2014;51:1551-72.

36. Belsley DA, Kuh E, Welsch RE. Regression diagnostics identifying Influential Data and Sources of Collinearity. 2nd ed. Hoboken: Wiley; 2004

37. Forthofer RN, Lee ES, Hernandez M. Biostatistics: a guide to design, analysis, and discovery. 2nd ed. Burlington: Elsevier Academic Press; 2007.

38. Rani M, Bonu S, Diop-Sidibe N. An empirical investigation of attitudes towards wife-beating among men and women in seven Sub-Saharan African Countries. Afr J Reprod Health. 2004;8(3):116-36.

39. Mihalic SW, Elliott D. A social learning theory model of marital violence. J Fam Violence. 1997;12(1):21-47.

40. Copp JE, et al. The development of attitudes toward intimate partner violence: an examination of key correlates among a sample of young adults. J Interpers Violence. 2019;34(7):1357-87.

41. Lawoko S. Predictors of attitudes toward intimate partner violence: a comparative study of men in Zambia and Kenya. J Interpers Violence. 2008:23:1056

42. Uthman OA, Lawoko S, Moradi T. Factors associated with attitudes towards intimate partner violence against women: a comparative analysis of 17 sub-Saharan countries. BMC Int Health Hum Rights. 2009;9:14.

43. Hindin MJ. Adolescent childbearing and women's attitudes towards wife beating in 25 Sub-Saharan African countries. Matern Child Health. 2014;18:1488-95

\section{Publisher's Note}

Springer Nature remains neutral with regard to jurisdictional claims in published maps and institutional affiliations. 